\title{
Educational Game "Saringman" to Familiarize Hygiene to Children Since Early Stage
}

\author{
Fiftin Noviyanto \\ Informatics Department \\ Universitas Ahmad Dahlan \\ Yogyakarta, Indonesia
}

\author{
Yana Hendriana \\ Informatics Department \\ Universitas Ahmad Dahlan \\ Yogyakarta, Indonesia
}

\author{
Bayu Nadya Kusuma \\ Informatics Department \\ Universitas Ahmad Dahlan \\ Yogyakarta, Indonesia
}

\begin{abstract}
Learning materials on the environment for children aged growth is quite difficult taught, with the lack of education, teaching materials and appropriate materials where children will easily absorb the material that accompanied the game. Delivery of content has not been used as a medium of learning tools. With the learning media in the form of educational games are expected to help the children understand the importance of keeping the environment clean, especially in terms of waste disposal. The strength of a research conducted, it produced an educational game app that contains materials about the importance of protecting the environment, especially in terms of taking out the trash for children between the ages of growth, which has been tested using black box test and alpha test. Based on the test results and Alpha Black Box test produces gaming applications that can helping the children to understand the importance of protecting the environment, with a view of the game that is user friendly, attractive, lightweight, has a weight of education and can be easily deployed to support learning about the importance of maintaining cleanliness environment.
\end{abstract}

Keywords: educational games; hygiene; environment

\section{INTRODUCTION}

More people realize that education is something that is very important for the progress of a nation and the State. With the proper education can impact on the development of technology, along with the growing impact of technology in the learning process, together with the impact on the learning process of education patterns also impact on human prosperity.

Environmental education is one of minimal education science applied to the child's age and growth. Therefore, to create a healthy environment in need of development in terms of nonformal education on solid and sustainable environment. To achieve such a case there should be an understanding of developments in technology and the sciences are ongoing in areas of existing application, the necessary role of academics to contribute to produce innovations of modern learning in addition to the conventional model of learning is done through a game.

Games are learning directly to the pattern of learning by doing. In a game there are a consequence of the player's game to get through the challenges that exist in a game play is run. Lessons learned patterns derived from failures that have been experienced by the player, thus encouraging not to repeat the failure next stage. From the pattern that developed the game, the player will be required to make the learning process independently, digging for information to enrich knowledge of strategy while playing. Thus the game offers a huge potential in building motivation in the learning process.

While only preliminary, results suggest that students experience higher intellectual intensity, intrinsic motivation, and overall student engagement when working in NIU-Torcs compared with traditional approaches to homework and class work in mechanical engineering. By reporting greater levels of challenge and concentration on the one hand, and enjoyment and interest on the other, the experience of students working in NIUTorcs is consistent with concept of engagement and learning through `serious games.' The finding is also consistent with previous research demonstrating that adolescents report the highest levels of engagement during active leisure activities, especially during games and sports [1].

Circulation of online gaming is increasingly penetrated into the elementary school. This has an impact on their behavior when they are poor school environment. Such concerns are not without reason to remember from year to year the number is not violence by children tends to increase [2].

Regulation of the Minister of Public Works number: 21 / PRT / M / 2006 highlights to achieve a condition of the people who live healthy and prosperous future, it will be necessary the existence of a healthy living environment, aspects of waste, then the word will mean healthy as conditions that would can be achieved if the waste can be managed well so clean from neighborhoods where human activities in it [3].

Environment Workshop (BKKL) which established the trash bank Bantul introducing various appropriate technologies in the field of environmental health, instill love in environmental health sciences for unversity students, encourage community participation in increasing the quality of the field of environmental health [4].

Thus it would need to be built gaming applications "building game education saringman since early for hygiene embed to children" so that children can play at once got a lesson about the importance of protecting the environment, especially in terms of disposing of waste in place.

\section{LITERATURE REVIEW}

Past research has ever made, entitled "Introduction to Game Development Education Animal Name In English For Elementary Students Learning Media Based Macromedia Flash" will be undertaken by Ghea Fatma Dewi [5]. Object of research in this study is the media making public elemtary school Somokaton, researchers revealed truly students difficulties in memorizing the sequence of letters in naming the animals, the results of these studies get very decent 
validation by experts of material, and with the media in the class or outside classes, students do not feel bored, help in memorizing and can help achieve the goal of learning [6].

The development of information technology, especially the gaming industry which is one of the growing gaming industry is important for brain development, to improve concentration and train properly and solve problems quickly because in the game there are various conflicts which requires us to solve it quickly and precisely [7].

Early Childhood Education (ECE) is very important to do well in a home environment as well as in the educational environment of pre-school. Education pre-school children at age 2 to 3 years is the formation of character, where education is stressed here in the picture, sound and movement combined with an attractive shape and color. At this age children begin to recognize the objects around it. The introduction of culture is also one of the curriculum in pre-school education [8].

The main objectives for developing the website are to educate the community on the benefits of performing the working memory test of the activity of the brain and improvements in social skills and improving poor academic and professional performance, especially in maths and reading comprehension [9]. A large number of literatures have been dedicated to the development of goal modeling, result modeling, ratings and rankings for games prediction [10].

The learning effectiveness and motivational appeal of a computer game for learning computer memory concepts, which was designed according to the curricular objectives and the subject matter of the Greek high school Computer Science (CS) curriculum, as compared to a similar application, encompassing identical learning objectives and content but lacking the gaming aspect [11].

The flow theory is used as a framework to facilitate positive user experience in order to maximize the impact of educational games. Especially, the factors that contribute to flow experience are discussed. The experiential gaming model can be used to design and analyse educational computer games. However, the model works only as a link between educational theory and game design and does not provide the means to a whole game design project [12].

The use of educational games in learning environments is an increasingly relevant trend. The motivational and immersive traits of game-based learning have been deeply studied in the literature, but the systematic design and implementation of educational games remain an elusive topic [13].

\subsection{Definition of Rubbish}

According to WHO, the rest of the waste is not refrigerate after something end process.

\subsection{Definition of Game}

Game meaningful "playing", game theory is a way of learning that is used to analyze a number of puz and individuals who demonstrate a rational strategy. The game consists of a set of rules that establish the situation play out of two or more of those groups to maximize their own victory or to minimize the opponent victory.

\subsection{Game History}

The world begins with the console-game console predecessors such as Atari, Nintendo, Super Nintendo (SNES), and SEGA that displays $2 \mathrm{D}$ game that is simple enough. Types of game play include:
1) Arcade / Side Scrolling
2) Racing
3) Fighting
4) Shooting
5) RTS (Real Time Strategy)
6) Role Playing Game
7) Simulation Games
8) Physics puzzle and puzzle

\subsection{Flash Game History}

Since the flash appears as a media tool for web animation, flash has undergone many evolutions in its development. Originally used for simple animation and minimal interaction, flash began to grow with the addition of Action Script 1.0 which takes the form similar to javascript [14].

In the flash 7 (Flash MX 2004), ActionScript 2.0 was introduced to the public with the addition of variable data types and syntax class.

On flash CS6 (Adobe Flash CS6), ActionScript 3.0 introduced the system embracing OOP (Object Oriented Progamming).

\subsection{Understanding Educational Games}

Educational game is a game that is designed or disposed of to horsefly stimulate including improved concentration and problem solving. Educational game is one type of media used to provide instruction adds its knowledge through a unique and exciting media.

\section{RESEARCH METHODS}

\subsection{Subject Research}

Subjects of this research is to establish the design and implementation of educational games with the game content is problem whose mother about lifestyle issues of protecting the environment by disposing of waste in its place is packed in educational flash game with the hope to increase awareness of children in protecting the environment by not disposing of waste in its place, implemented in programming language ActionScript 3.0 in Adobe Flash CS6.

This research is limited awareness of the importance of instilling an understanding of early childhood in protecting the environment, especially for not littering premises exciting educational game media and educate, then these limits are used in the manufacture of reference educational game. The sample used in this study were children aged 5-11 years.

\subsection{Methods Aggregation Data}

In the course of this research uses several methods to obtain accurate data, among others:

\subsubsection{Methods of Observation}

Methods of data collection related to the educational game is done by directly observing a similar game as "Jokowi Save Jakarta".

\subsubsection{Methods Library Studies}

Book study is the method of data collection is done by looking for information or data relating to research subjects educational games on the books, papers, related to the subject of research.

\subsection{System Design Waterfall Model 3.3.1 Needs Analysis Software}


Research methods of the game "SaringMan" using this type of research development (or engineered) where the concept of the system is represented by the application of interactive learning systems to improve children's education services to understand the environment.

\subsubsection{Systems and Software Design}

Saringman educational game application design, images, text, animation, and navigation in the form of software adobe flash circuitry, for character and entity elements drawn using CorelDraw X5, Adobe Illustrator CS6 and Photoshop CS6. Dubbing can be taken from the internet, windows movie maker, and android applications.

\subsubsection{Generalization Code}

Finding design that has been changed into program codes form.

\subsubsection{Testing}

Units are integrated and tested game into a complete system to ensure that the software requirements have been met.

\subsubsection{Maintenance}

The system is installed and used Maintenance includes rectification of errors that are not found in the previous step using the backlog.

\subsubsection{Testing Validation}

3.3.6.1 Black Box Test

Testing the system reliability in presenting information.

\subsubsection{Alpha Test}

Looking for some respondents were asked members feedback on the format of the level of hospitality applications.

\section{RESULTS AND DISCUSSION}

\subsection{Needs Analysis}

This research conducted, obtained the data necessary in the design of educational games using the waterfall method. These data are processed and customized into data that is ready to be implemented in a system.

Applications built has inter specifications:

4.1.1 The material is presented in a variety of text, animation and equipped with games to facilitate the delivery of materials and useful as an attraction decoy.

4.1.2 Game as the culmination of the material submitted by the actions in accordance with the input is entered.

\subsection{System Functional Requirements}

In making the application program saringman game needed an application that is able to perform functions, among others:

\subsubsection{Saringman}

- Having a throwing direction that can rotate 180 degrees.

- Having power brightener.

- Power lightening ejected by pressing the left click on the mouse.

\subsubsection{Enemy (tongpah)}

- The enemy carrying garbage

- Enemies affected by the power illuminator will change for the better.

\subsubsection{Strength brightener / Lightening Power}

- The power used saringman to sensitize the enemy so as not to pollute the environment.

- The power of lightening in the limit as much as 10 tosses.

- The power of lightening $=0$, the game is over.

4.2.4 Level

- There are 3 levels in the game

- Conditions of entry level 2 is defeated enemy at the first level.

- Conditions of entry level 3 managed to defeat the enemy in the second level

- Terms completing level 3, managed to defeat the enemy is hiding under a rock.

\subsection{Design System}

\subsubsection{Design Concept}

CAI concept models using simulation models and models of instructional games. Well-designed programs can motivate children in environmental education.

\subsubsection{Design Menu}

Facilitate the use of educational game app "saringman". It is necessary to design that divides the content into three levels. This application will be preceded by an intro to see the initial appearance before heading to the main menu. The design of the menu, among others:

- Intro

- Menu Utama

- New Game

- Animasi

- Main Level 1

- Main Level 2

- Main Level 3

- $\quad$ Credit

- Help

- Exit

\subsubsection{Graphic Design}

In the manufacture of button design, character, and background is divided into 3 phases:

4.3.3.1 Skatch Phase

At this stage of the sketch using software CorelDraw X5 in making the layout of the buttons, character, and background 4.3.3.2 Coloring Phase

On stage staining using Illustrator CS6 software in the coloring of the button, the character, and background 4.3.3.3 Dimensional Effects of Color Phase

At the stage of awarding the dimensions ranging from shadow color and gradation effects using Adobe Photoshop software.

\subsection{Implementation Design}

4.4.1 Character

4.4.1.1 Saringman

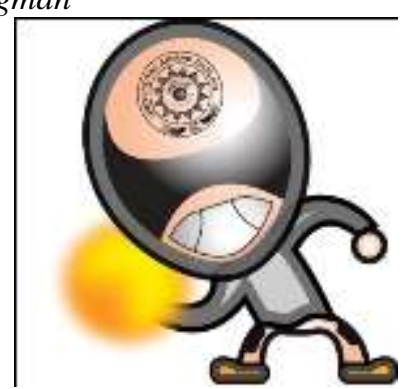


International Journal of Computer Applications Technology and Research

Volume 4- Issue 10, 750 - 754, 2015, ISSN: 2319-8656

Figure 1 Main Character

Figure 1 shows the main character a good ranger, and care about the environment.

\subsubsection{Enemy}

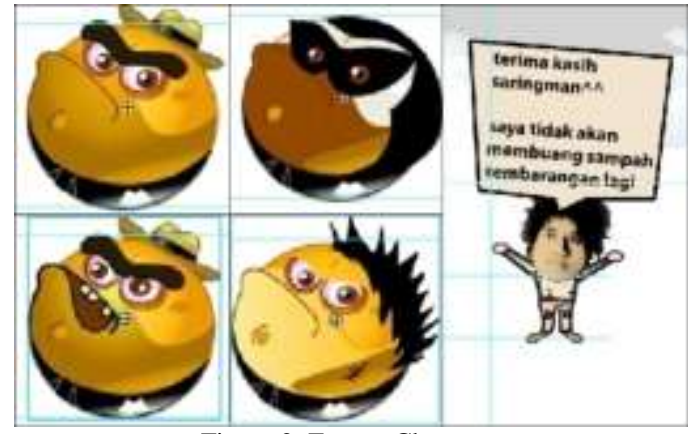

Figure 2 Enemy Character

Figure 2 shows the antagonist characters, citizens are less concerned who named tongpah.

\subsubsection{Lightening Power}

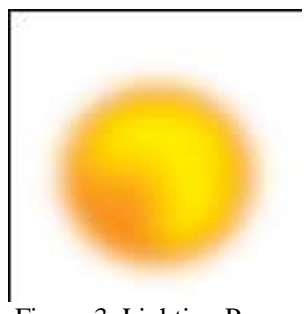

Figure 3 Lighting Power

Figure 3 shows the lightening power that the main character had to resuscitate the enemy character.

\subsubsection{System}

\subsubsection{Intro Мепи}

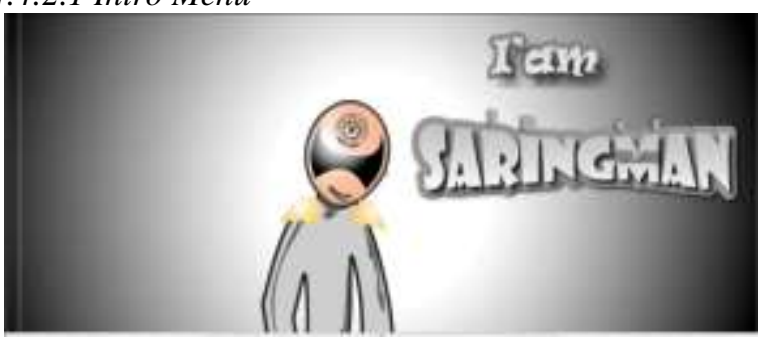

Figure 4 Intro Menu

Figure 4 shows initial appearance before entering the main menu contains intro introduction of characters and storyline.

\subsubsection{Main Menu}

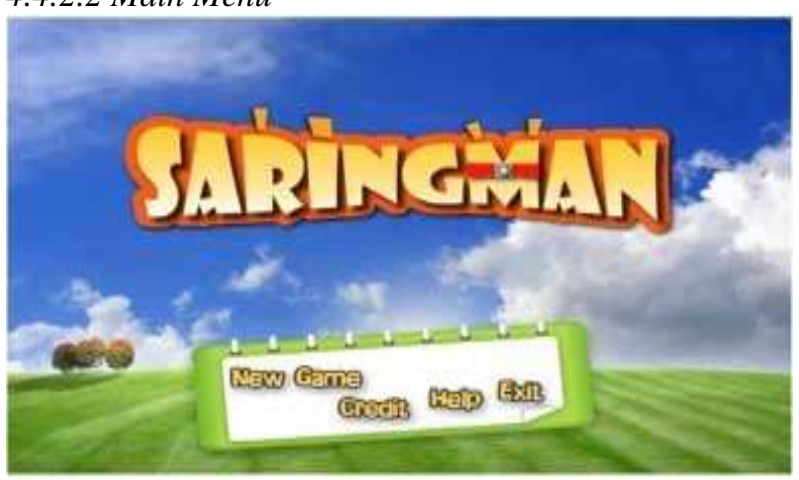

Figure 5 Main Menu

Figure 5 shows 4 contains the title and menu options that newgame, credit, Help, and Exit.

\subsubsection{Level Menu}

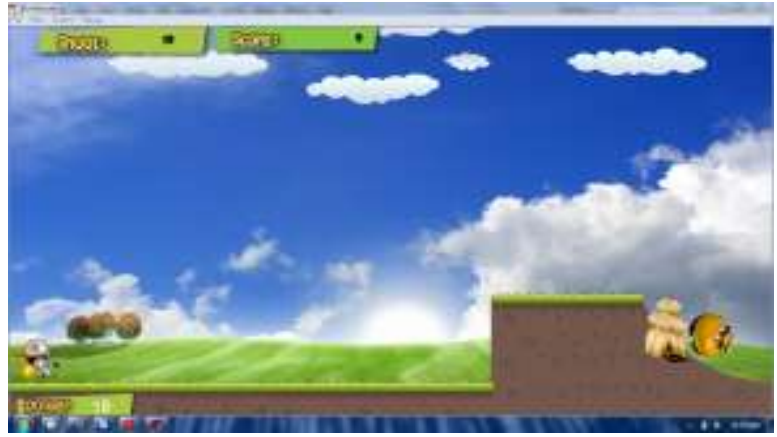

Figure 6 Level 1

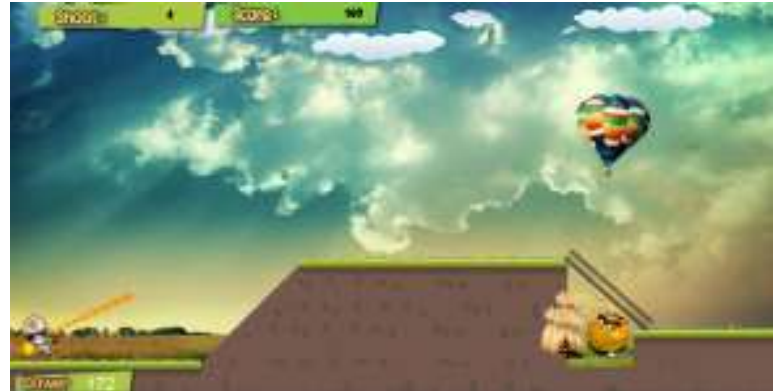

Figure 7 Level 2

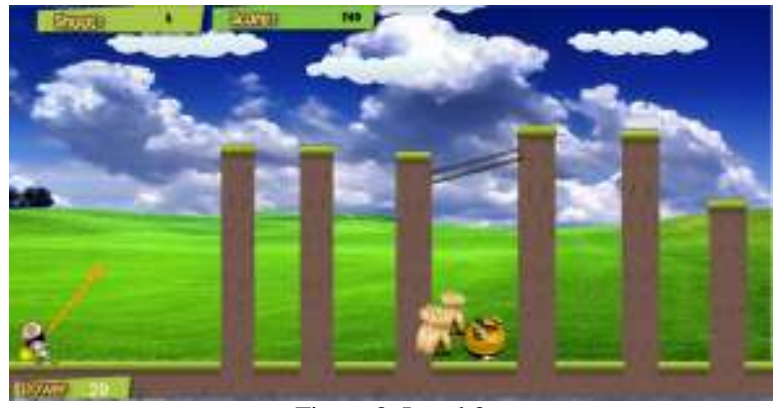

Figure 8 Level 3

Figure $6,7,8$ shows contains the core game from level 1 to level 3.

\subsubsection{Help Мепи}

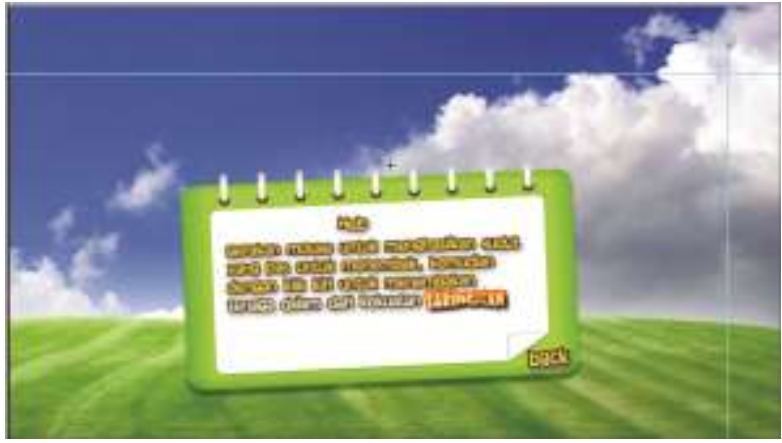

Figure 9 Help Menu

Figure 9 shows contains help on how to use the game of saringman. 


\section{CONCLUSION}

Based on the results of the analysis, design and implementation has been done before, it can take several conclusions, among others:

1) This research resulted in a software (software) about the game in order to inculcate hygiene education to children from an early age

2) Based on testing with tests conducted Blackbox method, this system is appropriate and can be used to help the understanding of consciousness for environmental menjada to children.

3) Testing alpha test. From the results of questionnaires that have been carried out concluded that the simulation is quite effective and attractive as well as facilitate the understanding of the importance of protecting the environment.

\section{REFERENCES}

[1] Coller, B. D., \& Shernoff, D. J. (2009). Video gamebased education in mechanical engineering: A look at student engagement. International Journal of Engineering Education, 25(2), 308.

[2] Joglo Semar News, June 2013. OnLine Game. pp.7

[3] Faizah, 2008, Household Waste Management Community based (Case Study in Yogyakarta), Tesis S-2 Universitas Dipenogoro Semarang.

[4] Diegenetika, 2013, Garbage Bank Indonesian version, first in Indonesia, http://banksampahbantul.com/news.

[5] Putri, Ghea, 2012, Game Development Education Introduction Animal Name In English For Primary Students Learning Media Based Macromedia Flash, Universitas Nergeri Yogyakarta.
[6] Setiana Nana, 2008, Decision support system based on the work of determining a web-based personality test, Universitas Ahmad Dahlan.

[7] Hendriana, Y., \& Ariyana, R. Y. (2015, May). Multimedia adventure game folklore "Doyan Nada" for improving the cultural understanding of Sasak (Lombok) to children. In Intelligent Technology and Its Applications (ISITIA), 2015 International Seminar on (pp. 251-256). IEEE.

[8] Zahrotun, L., Hendriana, Y., \& Saputra, D. 2015. Learning Media Introduction of Yogyakarta Culture For Early Childhood 2-3 Years. International Journal of Computer Techniques (IJCT) V2 (5): Page (1-5).

[9] Chiong, R., \& Jankovic, L. (2008). Learning game strategy design through iterated Prisoner's Dilemma. International Journal of Computer Applications in Technology, 32(3), 216-223.

[10] Uzoma, A. O., \& Nwachukwu, E. O. 2015. A Hybrid Prediction System for American NFL Results. International Journal of Computer Applications Technology and Research, 4(01), 42-47.

[11] Papastergiou, M. (2009). Digital game-based learning in high school computer science education: Impact on educational effectiveness and student motivation. Computers \& Education, 52(1), 1-12.

[12] Kiili, K. (2005). Digital game-based learning: Towards an experiential gaming model. The Internet and higher education, 8(1), 13-24.

[13] Moreno-Ger, P., Burgos, D., Martínez-Ortiz, I., Sierra, J. L., \& Fernández-Manjón, B. (2008). Educational game design for online education. Computers in Human Behavior, 24(6), 2530-2540.

[14] Griffith, Chris. 2010, Real World Flash Game Development. Canada: Publisher ELSEVIER Canada. 